\title{
AUDIT
}

\section{Use of a computerised maternity information system to improve clinical effectiveness: thromboprophylaxis at caesarean section}

\author{
Graham M Taylor, Clare A McKenzie, Gary J Mires
}

\begin{abstract}
An audit of the introduction of a protocol for thromboprophylaxis at caesarean section revealed over treatment of low risk women and the under treatment of high risk women. A routine computer generated risk assessment profile was introduced as part of a maternity information system. Reaudit showed a significant improvement in adherence to the thromboprophylaxis protocol in all risk groups. (Postgrad Med f 2000;76:354-356)
\end{abstract}

Keywords: thromboprophylaxis; caesarean section; computerised assessment

Thromboembolic disease is the leading cause of maternal death in the UK. ${ }^{1}$ This risk is significantly increased after caesarean section and hence national guidelines have been published in an attempt to reduce morbidity and mortality by thromboprophylaxis. ${ }^{2}$ These guidelines identify women in low, moderate, and high risk groups based on risk factor assessment. To be maximally effective it is essential that guidelines are adhered to in all cases. This study reports the use of a computerised maternity information system to improve the adherence to the thromboprophylaxis protocol.

Methods

A local thromboprophylaxis protocol based on the Royal College of Obstetricians and Gynae- cologists guidelines was developed at Ninewells Hospital and Medical School, Dundee and introduced in 1996 (table 1). In 1997, an audit was performed to assess the compliance with the protocol.

A retrospective analysis of the case notes of all women undergoing caesarean section at Ninewells Hospital Dundee between 1 December 1996 and 31 May 1997 was performed. A research assistant extracted information relating to the risk of thromboembolism and the prophylaxis administered from the case notes of all women who had undergone caesarean section during the study period. This information was compared with the expected management as described in the protocol and deficiencies identified.

After the identification of problems of frequent failure of adherence to the protocol, a computerised caesarean section operation note was devised within our maternity information system. This operation note incorporates a risk assessment profile for thromboembolism (fig 1). A programme identifies the risk category based on clinical information entered by the surgeon. A number of safeguards were introduced including the inability to print an operation note without entering the data required to assess risk. The system advises the appropriate treatment. After the introduction of the computerised system, a further audit was carried out for the six months from January 1998.

\section{Department of Obstetrics and Gynaecology, Ninewells Hospital, Dundee, UK G M Taylor C A McKenzie G J Mires \\ Correspondence to: Dr Graham M Taylor, Department of Obstetrics and Gynaecology, St James's University Hospital, Beckett Street, Leeds LS9 7TF, UK (e-mail: grahammtaylor@) hotmail.com)}

Submitted 12 March 1999 Accepted 22 September 1999
Table 1 Thromboprophylaxis protocol including the risk assessment profile and expected prophylaxis

\begin{tabular}{|c|c|c|}
\hline Risk group & Risk factors & Prophylaxis \\
\hline Low risk & $\begin{array}{l}\text { Uncomplicated pregnancy } \\
\text { Elective caesarean section }\end{array}$ & Early mobilisation and attention to hydration \\
\hline Moderate risk & $\begin{array}{l}\text { Emergency caesarean section } \\
\text { Age greater than } 35 \\
\text { Obesity } \\
\text { Pre-eclampsia } \\
\text { Para } 4 \text { or more } \\
\text { Gross varicose veins } \\
\text { Current infection } \\
\text { Prolonged immobility } \\
\text { Major current illness }\end{array}$ & $\begin{array}{l}\text { Unfractionated subcutaneous heparin (5000 units } 12 \text { hourly) and/or } \\
\text { graded compression (TED) stockings }\end{array}$ \\
\hline High risk & $\begin{array}{l}\text { Three or more moderate risk } \\
\text { factors } \\
\text { or } \\
\text { Absolute indication }\end{array}$ & $\begin{array}{l}\text { Unfractionated subcutaneous heparin (5000 units eight hourly) TED } \\
\text { stockings }\end{array}$ \\
\hline & $\begin{array}{l}\text { Personal history of: } \\
\text { DVT or pulmonary embolus } \\
\text { Thrombophilia } \\
\text { Antiphospholipid syndrome } \\
\text { Paralysis of the lower limbs } \\
\text { Extended major pelvic surgery }\end{array}$ & $\begin{array}{l}\text { (to be continued until the fifth postoperative day or fully mobile if } \\
\text { longer) }\end{array}$ \\
\hline
\end{tabular}

DVT $=$ deep vein thrombosis. 


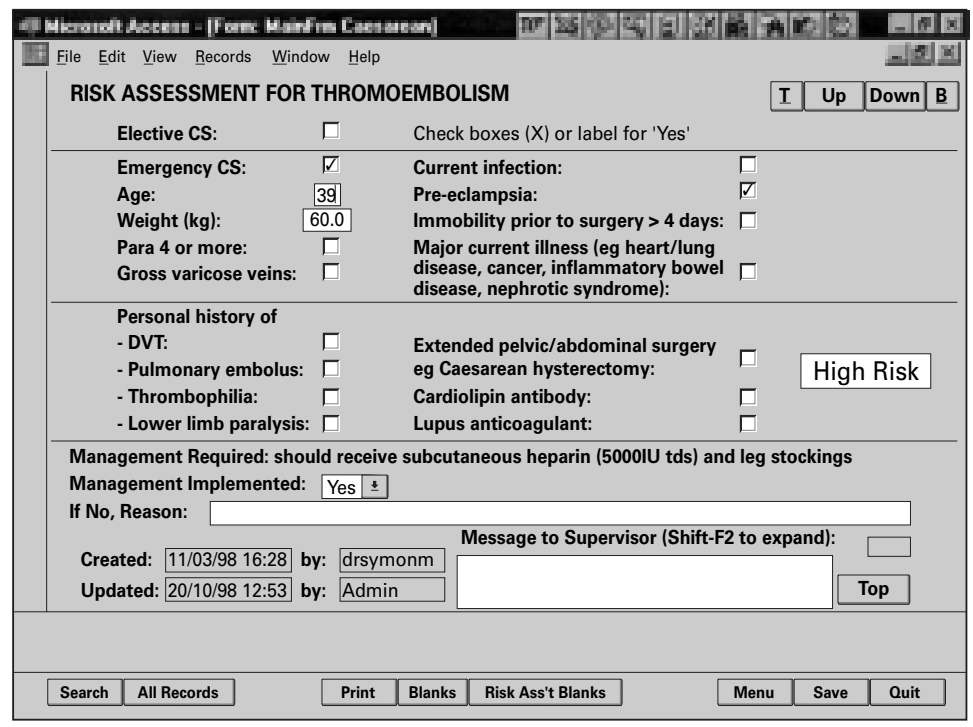

Figure 1 Thromboembolitic risk assessment sheet within the maternity information system.

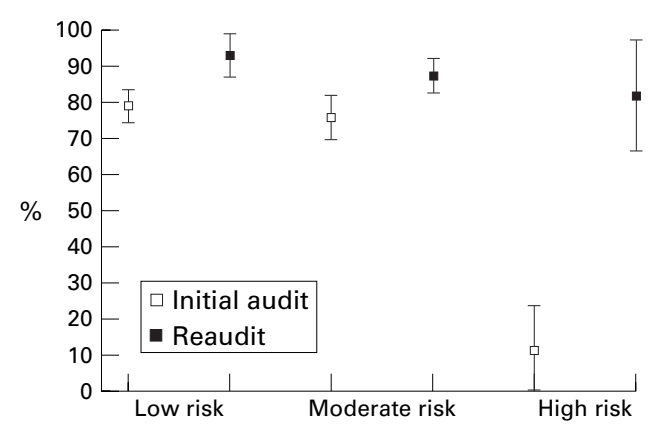

Figure 2 Proportion of women receiving appropriate thromboprophylaxis in each risk category with 95\% confidence intervals.

appropriateness of thromboprophylaxis in all risk groups as shown in fig 2 . The percentage increase in appropriate treatment was $14.2 \%$ (95\% confidence interval $8.6 \%$ to $19.8 \%$ ) in the low risk group, $11.8 \%(5.4 \%$ to $18.2 \%)$ in the moderate risk group, and $71.1 \%(65.1 \%$ to $77.1 \%)$ in those women categorised as high risk. Closer analysis of the small number of cases in which inappropriate prophylaxis occurred identified maternal age and maternal weight as the main risk factors overlooked.

Two hundred and eighty seven women underwent caesarean section during the initial audit period. Data were available for analysis in 270 cases. In the other 17 cases the case notes contained insufficient data for interpretation. The risk assessment profile categorised $65(24.1 \%)$ women as low risk, $179(66.3 \%)$ as moderate risk, and $26(9.6 \%)$ as high risk. The major risk factors in women in the moderate and high risk groups were emergency caesarean section, age over 35 years, obesity, and pre-eclampsia. Eighty five per cent of high risk women were categorised as such because of the presence of three or more moderate risk factors.

Thromboprophylaxis was deemed appropriate (heparin and/or compression (TED) stockings not given) in $52(80 \%)$ of low risk women and was felt to be excessive (subcutaneous heparin administered) in $13(20 \%)$. In the moderate risk group $137(76.5 \%)$ were treated appropriately with $42(23.5 \%)$ being under treated. However, in the high risk group only three $(11.5 \%)$ received the correct prophylaxis.

It was apparent that risk assessment was poor particularly in the high risk women. The main risk factors that were overlooked were emergency caesarean section, obesity, age over 35 , and pre-eclampsia. There also appeared to be some confusion as to the appropriate management strategy in the various risk groups.

\section{REAUDIT}

A total of 259 women underwent caesarean section during the second audit period. Fifty six women $(21.6 \%)$ were categorised as low risk, $180(69.5 \%)$ as moderate risk, and 23 $(8.9 \%)$ as high risk based on the risk assessment profile. The characteristics of each group were similar to the initial audit.

Treatment was appropriate in $53(94.6 \%)$ of low risk, 159 (88.3\%) of moderate risk, and 19 $(82.6 \%)$ of the high risk groups respectively. This showed significant improvements in the

\section{Discussion}

The introduction of a local protocol for thromboprophylaxis has been based on national guidelines. ${ }^{2}$ An audit of the introduction of this protocol initially identified a number of shortcomings particularly with respect to risk assessment and the under treatment of those in the high risk group. These problems mainly related to the failure of recognition of multiple risk factors in high risk women.

The use of computerised maternity information systems has gradually been increasing in the $\mathrm{UK}^{3}$ and the application of appropriate technology can be of benefit in both clinical practice and audit. ${ }^{4}$ Computerised systems have been developed to aid clinical diagnosis variable. Systems developed for the computer aided diagnosis of acute abdominal pain ${ }^{5}$ have been found to be more effective than a simple proforma in ensuring diagnostic accuracy. ${ }^{6}$ This type of system is dependent upon, and hence limited by, the quality of information entered by the operator. These problems are not easily overcome and other systems in which computers directly sample information and use algorithms to influence management, such as the computerised interpretation of cardiotocographs, have also encountered problems that limit their use. ${ }^{78}$

Adherence to protocols in maternity care has been reported as poor, ${ }^{9}$ and the use of information technology to improve compliance with protocols has been shown to be more effective than using a standard proforma. ${ }^{10}{ }^{11}$ Computerised systems may improve compliance but will be limited by the quality of the data entered.

The introduction of a computerised caesarean section operation sheet incorporating a risk assessment profile for thromboembolism has significantly improved adherence to the protoand management but their success has been 
col and hence clinical effectiveness. This study is an audit of clinical practice rather than a randomised controlled trial and we did not set out to evaluate the degree of improvement specifically related to the introduction of the computerised system. Although it may be argued that any change of process may have led to a statistical improvement in compliance in all risk groups, the greater than $70 \%$ improvement in the management of women in the high risk group is we believe greater than would be expected by audit alone. The system automatically calculates the woman's risk group based on an assessment of her risk factors and it does not allow an operation note to be printed without a decision being made about both the woman's thromboembolic risk and the type of prophylaxis to be employed. These features are felt to be safety mechanisms that could not be employed with a standard proforma, and substantially improve the system's effectiveness.

The performance of any computerised system is dependent upon the quality of the data recorded and in our reaudit failures of protocol adherence were almost exclusively due to incorrect entry of the woman's age and weight. These data were previously entered by the operating surgeon and were a potential source of error. In the light of the findings, alterations have been made to improve risk assessment by computerised calculation of maternal weight and age based on data routinely recorded within the maternity information system. The reliability of this information can obviously be questioned, however the woman's date of birth forms part of her unique identification number and this should allow the correct calculation of age in all cases. It is hoped that these changes will further increase protocol adherence.

The most recent confidential inquiry into maternal mortality ${ }^{1}$ has suggested that consideration should be given to prophylaxis in all women at risk of thromboembolism and our maternity information system is undergoing further developments to address this matter. It may also be possible to incorporate a computer generated prescription for the appropriate heparin regimen which can be countersigned by the surgeon at the time of printing. Although this audit set out to look only at thromboprophylaxis at caesarean section similar computerised risk assessments could be considered by units developing medical information systems not only in obstetrics but also in other specialties.

\section{Conclusion}

As thromboembolic disease remains a major contributor to maternal mortality appropriate prophylaxis after caesarean section is strongly recommended. Audit and the introduction of a novel computerised system for risk assessment has significantly improved our management of women undergoing caesarean section and maybe considered by other units identifying deficiencies in the implementation of local thromboprophylaxis protocols. Lewis G, Drife D, Botting B, et al. Why mothers die: report on Kingdom enquiries into maternal deaths in the United 1998.

2 Royal College of Obstetricians and Gynaecologists. Report of the RCOG working party on prophylaxis against thromboembolism in gynaecology and obstetrics. London: RCOG, 1995.

3 Yoong A, Das S, Carroll S, et al. A national survey to assess current use of computerised information systems in obstetcurrent use of computerised information syst

4 Maresh M. Computers in obstetrics. Br f Hosp Med 1992;47:336-9.

5 Adams ID, Chan M, Clifford PC, et al. Compute aided Adams ID, Chan M, Clifford PC, et al. Compute aided
diagnosis of acute abdominal pain: a multicentre study. BMF 1986;293:800-4.

6 De Dombal FT, Dallos V, McAdam WA. Can computer aided teaching packages improve clinical care in patients with acute abdominal pain? BMf 1991;302:1495-7.

7 Keith RDF, Beckley S, Garibaldi JM, et al. A multicentre comparative study of 17 experts and an intelligent computer system for managing labour using the cardiotocogram. $\mathrm{Br} \mathcal{F}$ Obstet Gynaecol 1995;102:688-700.

8 Chung TKH, Mohajer MP, Yang ZJ, et al. The prediction of foetal acidosis at birth by computerized analysis of intrapartum cardiotocography. Br F Obstet Gynaecol 1995; 102:454-60.

9 Yoong AF, Lim J, Hudson CN, et al. Audit of compliance with antenatal protocols. BMF 1992;305:1184-6.

10 Dombrowski MP, Tomlinson MW, Bottoms SF, et al. Computer generated admission forms have greater accuracy. $\mathrm{Am}$ puter generated admission forms

11 Steer P. A randomised controlled trial of computer data processing in the antenatal clinic. Br F Obstet Gynaecol 1998; 105:1219. 